\title{
Sonic Signs: Turning to, Talking About, and Transcribing Sound
}

\begin{abstract}
This chapter focuses on processes of representing and sharing sound in the sciences. How have scientists, engineers, and physicians talked about sound and transcribed sound into legible signs? What did they do to ensure the acceptability and standardization of their verbalizations and notations? Why did embodied forms of notation survive despite a wider trend toward mechanical objectivity? And in what contexts did scientists become interested in the epistemological relevance of sound in the first place? This chapter also introduces most of the case studies and listening technologies in more detail.
\end{abstract}

Keywords Sonic signs - Representing and sharing sound - Embodied notation - Automatic registration - Mechanical objectivity

\section{INTRODUCTION}

In 1954, Lawrence N. Solomon earned his doctoral degree in psychology at the University of Illinois with a study on complex auditory stimuli. The stimuli he examined were underwater sounds. These were highly relevant in undersea warfare, giving sonar operators information on whether, for instance, battleships from their own country were coming home or enemy submarines were approaching. Solomon wanted to know how sonar operators made sense of such sounds, and he was especially intrigued by the informal "sonar vocabulary" the operators had 
developed to distinguish between and communicate about the sounds that they heard. The sonar men described sonic signs with words such as "heavy," "light," "bright," "dull," "hard," and "soft," making Solomon "suspect that synesthetic or metaphorical thinking is operative in this judgmental process." He assumed that the sonar operators had "intuitively turned for aid" to "these qualitative "meaning' dimensions" to discriminate between the sounds (1954: 3-4).

Ultimately, Solomon's aim was to operationalize such meaning dimensions for psychological research. His dissertation contributed to the rise of the "semantic differential," a method for measuring meaning that was developed by Solomon's doctoral advisor Charles E. Osgood and his colleagues. The method asks test subjects to rate their attitude to a particular issue on a scale between two opposite adjectives- "heavy" and "light" in Solomon's example. It has been adopted in fields as diverse as psychology, acoustics, music, linguistics, business research, and political science to measure attitudes, opinions, values, and aesthetic perception. ${ }^{1}$ The question of how to recognize and talk about sound thus informed the development of a test that is still widely used today.

The sonar men's meaning-making strategies also show the relevance of describing sound in the process of building knowledge on sound. Their synesthetic and metaphorical verbalizations of sound are instances of representing and sharing sound-the topic of this chapter. Other examples include the use of onomatopoeic terms; drawing lines, curves, and dashes; working with staves, keys, or notes; and having machines like spectrographs transform sounds into legible signs. Those who fostered listening for knowledge defined or redefined their interests as objects of sonic investigation, as issues that could be understood through practices of listening. To make their case, they not only tried to find ways of talking and writing about sound, but also of recalling sounds days, weeks, months, or even years after these had been audible. They tried to capture sound in terms that did justice to their questions and enabled them to share the sounds with their peers. They promoted strategies for analyzing sonic signs after the event. And they attempted to convince colleagues of, and initiate novices into, the sonic patterns they thought they could hear. These were the issues professionals and scholars working with sound dealt with and translated into practices that expressed both their sonic skills and ways of knowing.

This chapter covers both non-automatic, embodied practices of representing and sharing sound, such as verbalization and manual forms of 
notation, and the use of automatic, mechanical registrations of sound, such as audio recordings and sound spectrograms. This dual approach is important because in some fields, the development of manual notation has been closely associated with the availability of automatic recording technologies. The transcription of non-Western music, for instance, started to flourish only after the introduction of the phonograph (Stockman 1979), and naturalists' embrace of sound recording technologies as a way to bring bird sounds home gave new salience to questions of how to properly transcribe these sounds.

What notation systems did scientists, physicians, and engineers who listened for knowledge employ in their research and teaching, and where did those systems come from? How did existing and new forms of notating and recording sound co-constitute both the objects of research and the ideal researcher him- or herself? And under what conditions did non-automatic forms of representation survive alongside automatic forms? The crux of my answer will be that manual notation and other forms of embodied representation survived notably in situations where the required auditory knowledge depended on immediate, on-the-spot judgments and communication by trained experts with jurisdiction, as well as in situations where the gestural nature of manual notation had its own epistemological and didactic value.

In addition to discussing the relevance of representing and sharing sound for the process of making knowledge out of sound, this chapter unpacks the Sonic Skills project's core case studies by detailing the sources behind them. It also contextualizes the situations in which particular experts began to feel the need to listen to their objects of interest in the first place. A more systematic discussion of the purposes of listening, and of ways of listening in the sciences, will be presented in Chapter 3.

\section{Hazy Sounds: Verbalizations ANd Descriptions of the Audible}

Solomon's research on sonar was done during his summer job in San Diego as a psychologist at the United States Navy Electronics Laboratory in the early 1950s (Solomon 1954: 65). Sonar equipment enabled navy submarine operators to pick up and amplify sound signals in water, such as those produced by ship propellers. They had to distinguish relevant from irrelevant sounds and label the sources correctly by 
honing in on subtle changes in the sound's loudness, pitch, timbre, and rhythmic pulse. To understand these processes, Solomon wrote, one had to take into account not only the physical properties of the sound stimulus - intensity, frequency, complexity, and duration-but also what the stimulus meant to the person responding to it. $\mathrm{He}$ also argued that the relationships between "certain stimuli and their connotative associations" were "lawful" (Solomon 1954: 9).

To find those laws, Solomon designed a list of fifty pairs of attributes for the assessment of passive sonar sounds, such as heavy-light, smoothrough, powerful-weak, hot-cold, green-red, masculine-feminine, clearhazy, and mild-intense (Solomon 1954: 27). Many of these words came from lists of recognition cues employed by the sonar operators themselves. Solomon then asked fifty sonar men to listen to a selection of Navy recordings of passive sonar sounds, and rate each one on a scale of 1 to 7 for all fifty attributes. The greatest consistency in ratings was found in the pairs heavy-light, mild-intense, and clear-hazy (Solomon 1954: 43-45). Comparing these results with those published by Charles Osgood on other groups, Solomon concluded that notions expressing "clarity," such as clear-hazy, and "security," such as mild-intense, were most specific to what he called "sonar culture" (Osgood et al. 1957: 68). The clarity attributes expressed the ways in which sonar men selected "a coherent noise signal from a background of noise," and the security attributes how they discriminated between the most "heavily armed" vessels and less dangerous ones (Solomon 1954: 44, 48).

Of course, correctly interpreting the enemy's sound was often crucial for survival in war situations. From understanding the impact of acoustic shadows-hills, bushes, snow, and wind refracting or absorbing sound so that one might not hear an enemy attacking - to detecting and locating hostile artillery or uncovering secret atomic testing; sound could be the difference between life and death (Ross 2004: 275; Schwartz 2012: 573; Volmar 2012, 2013, 2014). The wide range of technologies to enhance listening in World War I was mentioned in the previous chapter, but occasionally, sound was even used to fake military actions. At the end of World War II, a US "ghost army" acoustically misled the Germans by suggesting an attack on one position while assaulting another. This sonic deception was achieved by replaying sound recordings of military operations-tanks driving, bridges being constructed, soldiers screaming - through loudspeakers mounted on "sonic cars" (Gerard 2002: 100-121, 277-292; Goodwin 2010: 
4l-43). Understanding sound and communicating about it comprehensibly, then, were extremely important for the military, and especially for sonar experts. Consequently, sonar operators received extensive training in sound detection and recognition, largely behind closed doors. Solomon, for instance, kept the exact sources of the sounds listened to by his sonar respondents secret for security reasons (Solomon 1954: 19).

In the worlds of the doctors, mechanics, engineers, and scientists we studied, unlike in the military settings, the sounds were usually not kept secret. However, just as much importance was attached to the creation of taxonomies of words and notation systems for sounds, intended to classify and standardize descriptions in order to consistently distinguish sounds from each other. That undertaking was far from easy. Drawing up a classification was one thing; having it adopted beyond a local culture like that of sonar quite another. The same applied to the codifications that mapped particular sounds onto particular problems. And the debates about classification, standardization, and systematic sound mapping tended to intensify even more once groups of experts shifted from unmediated listening to mediated listening, each with their own instruments.

As Jens Lachmund phrased it wonderfully when discussing the early nineteenth-century introduction of the stethoscope in medicine, codification systems "transformed fleeting auditory experiences into a world of communicable signs and meanings" (Lachmund 1999: 420). In medicine before the nineteenth century, listening to the body had only been possible by placing one's ear upon the body-something often felt to be inappropriate, especially if the patients were ladies. In the second half of the eighteenth century, an alternative arose: "percussion," a diagnostic listening to the sounds produced by knocking on the body. The stethoscope conveniently allowed doctors to physically distance themselves even further from the patient, while also enabling them to listen to bodily sounds with more focus through "auscultation." The resulting perceptual distance and isolation of the sounds of interest afforded, Tom Rice has argued, a process of "acoustic objectification" (Rice 2013: 126). The transition from the monaural stethoscope to the binaural stethoscope in the early 1850s helped to create a "enclosed aural pathway" between the doctors' ears and the patients' bodies, the sounds of which could be amplified with electronic stethoscopes from the 1920s on (Van Drie 2013: 176). ${ }^{2}$ 
Listening for knowledge with the stethoscope was not only dependent on acoustic objectification and an enclosed aural pathway, however. Just as important was the communication about what doctors were aurally attending to. Working in Paris in the early nineteenth century, René Laennec presupposed a direct relationship between particular pathological conditions and certain "pathognomic signs" he heard with his stethoscope, which he classified as signs of the voice, respiration, rattles (fluid-induced alterations in respiration), and circulation (Lachmund 1999: 425). To distinguish between these sonic signs, he made a wide range of comparisons with everyday sounds such as "the satisfied purring of cats being petted," "the tinkle of weapons during military exercises," or "the sound produced when a string of bass is beaten with a finger" (Laennec cited in Martin and Fangerau 2011: 303, and in Lachmund 1999: 425-426). Laennec did not only invoke everyday soundscapes, however; he also used visual imagery, such as "bubbles like those which are produced by blowing with a pipe into soapy water," to capture what was happening inside diseased bodies (Laennec cited in Lachmund 1999: 426) He considered the hospital setting indispensable for acquiring stethoscopic skills, not only because of the number and diversity of patients available for practicing but also because of the opportunity to check assumptions retrospectively through autopsy-again seeking visual analogies. Colleagues working in the same tradition, such as Jules Fournet, created increasingly fine-grained and multilayered classifications drawing on the tradition of botanical taxonomies, and added "synoptic tabular visualization of auscultation sounds and their meanings" (Lachmund 1999: 428).

In contrast, the Viennese doctor Joseph Skoda postulated that physics and acoustic phenomena, such as reverberation and amplification, were also needed in order to establish a convincing relationship between sounds and pathologies. This attention for the acoustic milieu of sounds resulted in a less detailed classification, as not all deviating sounds could be linked directly to particular health problems. Skoda still employed metaphors, and also used onomatopoeic words such as "tik-tak, tom-tum" and "dobm-lopp" for heart sounds (Martin and Fangerau 2011: 304), but he did not seek to create a complex taxonomy assigning one sound to one cause. Instead, he invited doctors to mimic particular sounds with their own body in order to understand the acoustic phenomena that helped to define the sounds of pathological conditions. In addition, he developed a system of "differential 
diagnosis," in which signs were not universal and positive references to particular pathological conditions, but starting points for a negative strategy based on excluding certain interpretations. An audible intensification of a patient's voice, for example, might be the acoustic effect of "thickening of the pulmonary tissue," but its specific cause-the disease behind it-had to be found by excluding alternative interpretations through anamnesis and other techniques (Lachmund 1999: 432). This strategy, Lachmund argues, was embedded in an experimental laboratory tradition of medical research in the German-speaking area, where doctors had access to fewer patients than did French doctors with their large hospitals. In France, tacit sonic skills could be transmitted within an apprenticeship context; learning sounds from textual descriptions alone was much harder. The alternative was to reject Laennec's and his followers' straightforward tables of sonic signs and related conditions in favor of differential diagnosis.

In the context of twentieth-century German automotive engineering, a predominantly tacitly transmitted system of sound mapping developed, as Stefan Krebs has shown by analyzing German automotive trade journals, car mechanics' handbooks, the Volkswagen and Robert Bosch company archives, and interviews with former car mechanics. Just as in French medicine, an apprenticeship tradition enabled a culture of locally taught, and locally understood, verbal descriptions of sound to arise in German car mechanics. In the early 1930s, German car mechanics succeeded in having their trade legally protected in craft guilds (Krebs 2012a: 200). The move responded to public concerns about the quality of car repair, and helped them to demarcate their work from ad hoc mechanics-but it also secured them jurisdiction over the diagnosis of alarming car sounds at the expense of motorists. Motorists' handbooks had long instructed drivers to monitor and diagnose their cars' functioning by listening while driving (Bijsterveld 2012: 161; Bijsterveld et al. 2014; Krebs 2012a: 99-102; 2013: 92); now, car mechanics increasingly labeled motorists as either "noise fanatics" or "noise phlegmatics." Noise fanatics brought their cars to the garage in response to the slightest, often wrongly understood sounds, whereas noise phlegmatics kept driving even if their cars were simply screaming for help (Krebs 2012b: 96). The perfect motorist, mechanics believed, would have just enough auditory knowledge to identify sounds that signified car problems, bring his car to the garage, and leave the actual diagnosis to the mechanic. 
With a three-year apprenticeship ideally culminating in a journeyman's certificate and a four-year on-the-job curriculum for the master craftsman's diploma, mechanics were taught in a learning-by-doing context. On the shop floor, novices were supposed to develop not only technological knowledge and mechanical proficiency, but also sensory skills. Two short series of articles published in brochures and a journal for apprentices in 1956 and 1965 explained the importance of these sensory skills in diagnosis. The "expert eye" expressed itself in an "intuitive gaze" that enabled the mechanic to "notice every deviation from the 'normal picture' ... such as oil slicks or rust stains" right away. The "expert nose" would be able to smell gasoline or burned cables, and tasting liquids could be useful, although potentially dangerous to the mechanic's health. The "expert ear" was crucial as well- "probably even more important than the expert eye," one author had it. "Listening to recognize the actual problem, listening in, with a listening rod or just a screwdriver, to locate it - that is real diagnostic practice" (Anonymous 1956, 261-263, cited in Krebs 2014a: 360-361; 2014b: 80). This was anything but simple to learn, because the "real art of 'listening' to automobiles only starts where one complex sound dissolves into many single sounds and the mechanic's ear will be able to connect a particular source of noise with each one of them" (Anonymous (Teil II), 1965: 235, cited by Krebs 2014a: 361; 2014b: 81).

An experienced mechanic, in this view, would be able to distinguish a problematic, discontinuous "prr-prr-prr" from a reassuring, continuous "prrrrrr" and know that it signified an issue with one of the cylinders. He would be able to key such sounds into his theoretical knowledge of how subsystems in the car affected each other, and might check, for instance, whether a particular sound disappeared or changed in pitch once specific parts were separated from the engine and drive train or the gears were moved up and down. Analyzing the sound's rhythm through its periodicity was another significant strategy. If the sound was audible only every second revolution rather than every revolution, the fuel pump might be broken. For the act of listening, mechanics used their hands to shield their ears from disturbing noises, or employed tools such as rods, screwdrivers, and stethoscopes. Some of these stethoscopes had exchangeable probes - tips or bells - to vary between listening to large and small spots, and were exclusively used to reach specific parts of the car such as the engine block or individual bearings. One additional instrument, a device for testing the circuits in generators and starting 
mechanisms, had an auditory display in the form of a buzzer to which mechanics could listen with headphones (Krebs 2014a: 362).

Sensory skills and diagnostic listening were not so highly valued in all circles of car mechanics, however. The United States, for instance, witnessed a similar "repair crisis" to Germany's in the 1930s, but a very different response prevailed. Whereas German mechanics had successfully joined forces to rhetorically undermine motorists' auditory diagnostic capabilities and claim diagnosis through listening as their exclusive trade expertise, US motorists effectively turned against car mechanics. They questioned the workmen's choices-were their expensive repairs really necessary, or based on subjective assessments favoring their wallets? Car mechanics responded by trying to enhance the transparency of their actions, resulting in forms of diagnosis that used meters such as "the voltmeter, ammeter, and ohmmeter, as well as various compression or vacuum gauges" instead of the senses (Krebs 2012b, 2014a: 365). I will return in Chapter 4 to this move towards visual diagnostics in US automotive repair.

In the German automotive world, diagnostic listening survived much longer, though mechanics and automotive engineers invested less sustained effort in refining and ordering the descriptors of car sound than the medical world had done for bodily sounds. To be sure, the German automotive press published lists, tables, and fault trees describing sounds and their causes. Onomatopoeia were little used, but terms such as whining, rumbling, hammering, pinging, and knocking were ubiquitous, at times further specified as "metallic knocking," "damped knocking," or a "muffled clang" (Anonymous 1932: 81-82, cited by Krebs 2012b: 88). One article from the late 1950s explicitly listed twenty-five such suspicious sounds. Several authors, within and outside Germany, acknowledged that the automotive world used different sound labels for the same phenomenon (Krebs 2014a: 363; Zwikker 1934: 70). In turn, one particular sound, such as the knocking of engines, at times compared to the muffled rumble of a kettledrum, could be a sign both of machine wear and of gasoline problems (Bijsterveld 2007: 15). Most authors did not worry too much about such ambiguities because they anyway regarded written accounts as unhelpful for learning diagnostic listening-experience was the key to the mechanic's training. The automotive world could afford to neglect the construction of unambiguous descriptions either because diagnostic listening was firmly located within the jurisdiction of mechanics and their tacitly transmitted strategies for 
connecting textbook knowledge to sensory observations on the shop floor, or because it had simply been replaced by meter reading under pressure from critical customers.

The medical world, in contrast, continued to discuss the disambiguation and standardization of descriptions of sound, increasingly bearing in mind the need for international scholarly exchange. In the second half of the nineteenth century, a German physician described the French medical classifications of sound as "Chinese" in their complexity and incomprehensibility (Niemeyer 1868: 19, cited in Martin and Fangerau 2011: 304). The suggested alternatives included differential diagnosis as well as systems for graphic notation of heart sounds, which I will discuss in the next section. In respiratory medicine, the "universal semantic" that would standardize the descriptors of bodily sounds and their meaning became an elusive holy grail (Reichert et al. 2008: 2). The International Lung Sounds Association, established in 1975, fostered the "exchange of ideas and experience" in respiratory medicine, and hoped that "comparisons of methods of recording, analyzing, and describing lung sounds" would "reduce ambiguity." Accordingly, it instituted a Committee on Lung Sound Nomenclature, but did not expect that "a new and improved set of terms will be agreed upon and recommended for instant acceptance by the medical profession." 3 Sure enough, in 2000, a group of physicians and scientists collaborating on software for Computerized Respiratory Sound Analysis (CORSA) still found it necessary to first collect and define over 160 relevant terms. Among these was the "crackle," an "[a]dventitious, discontinuous, explosive sound occurring usually during inspiration" (Sovijärvi et al. 2000: 600).

Despite such attempts at international standardization, doctors still referred to everyday sounds of their own choice when introducing students to the mysterious world audible with the stethoscope. We know this from the studies undertaken by Anna Harris and Melissa Van Drie. Harris, a medical graduate turned anthropologist, carried out an ethnography of listening practices at a Melbourne hospital medical school for five months in 2013, and observed training in physical examination at the Maastricht University Skills Lab the year after. In Melbourne and Maastricht, she performed a total of seventeen formal semi-structured interviews with doctor-teachers and students, as well as talking informally to them, to nurses, and to other hospital staff. She recorded the interviews and her auditory observations of hospital sounds, and made drawings of what she saw teachers and students themselves drawing. Van Drie 
selected the most widely reprinted and widely cited British, American, and French textbooks on physical examination and lung auscultation guides from 1950 to 2010, and searched medical libraries and archives for evidence on other media employed to teach stethoscope listening. As noted in Chapter 1, both Harris and Van Drie focused on the teaching of the respiratory cycle, but without neglecting the training of students to listen to the cardiovascular system.

Hardware for student instruction, Van Drie (2013; Harris and Van Drie 2015) shows, evolved from collective stethoscopes with multiple earphones attached to one bell (1880s), via electronic collective stethoscopes (1920s) and plug-in electronic stethoscopes attached to a lecture hall broadcasting system (1960s), to today's mannequin simulators, and from gramophone recordings as textbook appendices (1930s), via audio cassettes to be listened to without (1950s) or with a stethoscope (1970s), to present-day compact disks and mp3 files, enabling students to listen to exemplary bodily sounds. Nevertheless, metaphors remained helpful. They were both culturally and historically specific: Dutch medical students nodded in assent on hearing an instructor explain that pleural friction rubs sounded like "feet crunching in snow," but that would hardly have been self-evident to students living closer to the equator. An Australian professor had long been accustomed to describing the sounds of pleuritic rubs as squeaking leather, but acknowledged that this ceased to be effective when Melbourne trams stopped using leather suspension components. The same professor, however, did not yet wholeheartedly endorse the more recent description of fine crackles as Velcro being pulled apart (Harris and Van Drie 2015: 103). And Sarah Maslen (2015) has noted that physicians still employ not only onomatopoeic signifiers, such as "lub," "dub," and "lub-di-dub" for the first, second, and third heart sound, but also metaphors: the fourth, pathological heart sound is "like a hose directly hitting against a bucket." Such descriptions, Maslen believes, help students to memorize instructions, and-bearing in mind George Lakoff's and Mark Johnson's work on the metaphors we live by-“to structure understanding" (Maslen 2015: 61, 64).

The contexts into which descriptions, classifications, and codifications of sound are intended to intervene are thus crucial for their form and for their acceptance as relevant expertise. I will return to this issue later in the chapter, but let me first discuss yet another way of describing sound. As they seek words for sound, doctors, engineers, and mechanics have occasionally used musical metaphors. Laennec referred to bass 
strings, 1920s engineers in the automotive world to kettledrums-at times picturing a noisy engine as an unruly big band (Bijsterveld and Krebs 2013: 19). The actual use of musical notation was rare, however, even though Laennec used it to put heart sounds on paper (Lachmund 1999: 428; Martin and Fangerau 2011: 305). In ornithology, by contrast, musical staff notation was a dominant practice at least at the dawn of the field as academic discipline, around 1900. One key to understanding this difference between the sciences is the conceptualization of the sounds being studied. Initially, bird naturalists saw themselves as studying not bird sound, but bird song, a choice of terms that expressed their early inclination to classify bird vocalizations as a form of music. It therefore seemed perfectly natural to notate bird sound in musical staff, as Joeri Bruyninckx (2013) showed in his study of American, British, and German ornithology.

Bruyninckx systematically analyzed key naturalist and ornithological journals that entered the scene between 1880 and 1980, The Auk, The Condor, The Wilson Bulletin, Journal of Field Ornithology, Ibis, British Birds, Journal für Ornithologie, Animal Behaviour, and Behaviour. He also traced the rise of the bird-sound recording archives, studying in most detail the earliest of these-the Macaulay Library at Cornell University in New York, the British Library of Wildlife Sounds in London, and the Tierstimmenarchiv at the Humboldt University in Berlin. Additional sources were the autobiographical accounts of pivotal players in the world of bird studies in the past, and oral interviews with their counterparts in the present.

\section{Artful Drawings: Musical and Graphic Notation}

In the early decades of the twentieth century, most ornithologists used musical staff notation, often in combination with syllabic notation of onomatopoeic expressions. The British ornithologist Walter Garstang, for instance, wrote syllables such as "sip, sip, sip, see! Tee, tew, wee, tew! Wit-ty, wit-ty, wee-wee, wee tew!" below his musical score of the Willow-wren (Garstang 1922, cited in Marsden 1927: 342). Some even expanded such melodic musical scores into "four-part" harmonies that could be played on a piano or other harmonic musical instruments (Mundy 2010: 181). In fact, composer Cornell Schmitt and naturalist Hans Stadler advocated musical staff notation as the scientific method par excellence, on the grounds that its mature conventions provided a 
"precise and scientific way of comparison" (Schmitt and Stadler 1913: 394, cited in Bruyninckx 2013: 40). Musical training, claimed biologist Henry Oldys, allowed naturalists "to observe important features that are quite certain to escape the attention of one whose musical ear has never been cultivated" (Oldys 1916: 20, cited in Bruyninckx 2013: 39).

This reliance on musical notation was fueled in part by the expectation that studying birdsong might disclose the origins of human music, a notion that itself drew on the Darwinian argument that birdsong, like plumage, emerged from the mechanism of sexual selection. In the 1910s, opinion in ornithological journals began to diverge on whether birdsong was indeed a function of sexual selection, or rather of natural selection or simply imitation. It was also unclear whether birds could themselves be ascribed aesthetic sensitivity. In the 1930s, the rise of ethology pushed aside the issue of the bird as a proto-artist: biologists such as Konrad Lorenz and Nikolaas Tinbergen "conceptualized animal behavior instead as compulsive, functional and automatic" (Bruyninckx 2013: 45). Their approach marked the culmination of another gradual shift in ornithology since the 1880s, from a focus on collecting, describing, and classifying dead birds for fauna taxonomies to a focus on studying birds live, especially in their natural settings.

In line with this new type of interest in birds, it was in a 1904 field guide for wild bird life that the American amateur naturalist Ferdinand Mathews noted his difficulties with musical notation when trying to describe a Bobolink song. The result was a remarkable transcript. ${ }^{4}$ Mathews admitted he had "never been able to 'sort out' the tones as they passed at this break-neck speed," so that "the difficulty in either describing or putting upon paper such music is insurmountable" (Mathews 1904: 49, cited in Bruyninckx 2013: 29-30). In Bruyninckx's words, the drawings that Mathews proposed instead "started off in a traditional grid of quarter and eighth notes but quickly oscillated beyond the conventional dimensions of relative time and pitch," showing notes "wildly bouncing and receding back in time" (Bruyninckx 2013: 30). Another American amateur naturalist, Aretas Saunders, argued that musical notation "has been made primarily for the recording and rendering of human music and birds do not usually sing according to such standards." Soon after, he rhetorically asked whether ornithologists should "change such a song in order to make it fit our method?" Would such a procedure express "scientific accuracy" (Saunders 1915: 173, and 1916: 104, cited in Bruyninckx 2013: 46-47)? Notating bird sound in terms 
of Western music was increasingly seen as endangering a scientific understanding of bird vocalization.

The American naturalist Lucy Coffin promoted the use of "new musical scales akin to Chinese or Gregorian ones" as well as a wider range of instruments, "including xylophone, banjo, zither, bassoons, and piccolo," to represent bird sound more precisely (Coffin 1928, cited in Mundy 2009: 208). British poet William John Murray Marsden wrote that he was looking for "musico-ornithologists" capable of effectively notating the song of birds, as the "diatonic notes, on a keyed instrument, are 'not a bit like' what one hears from the coral beak." He had been able to "whistle and fiddle" a few cries and phrases himself, but he suspected that "with a few pretty well recognised exceptions, no bird's song-or speech, or whatever it is-can be expressed in tones of our musical notation. And I want somebody, now that, as I understand, our diatonic system is undergoing Promethean and Protean experiences in younger hands, to be inspired to bring together again the birds and ourselves" (Marsden 1927: 339-341). Marsden was probably referring to the composers of his time and their experimentation with new notation forms. Composers such as Ferruccio Busoni, Luigi Russolo, and Henry Cowell aimed to free contemporary music from the limits of traditional musical notation and enable the notation of microtones, as well as new rhythmic and harmonic complexities that better expressed modern urban life and composers' imaginations (Busoni 1962/1907; Russolo 1986/1916; Cowell 1932).

The type of graphic notation that Aretas Saunders suggested for bird vocalizations similarly permitted the representation of microtones. ${ }^{5}$ Saunders did away with conventional staves and their relative organization of pitch and time, instead plotting pitch in terms of absolute frequency-even though this frequency was still indicated using musical notes. He recorded duration, too, in absolute terms, that is, in seconds. This met with fierce opposition. For the musician and naturalist Robert Moore, a dedicated promoter of musical notation in the American Ornithologists' Union, meter and rhythm were such crucial elements of birdsong that their registration must not be left out (Bruyninckx 2013: 47). Clearly, opinions on the best methods of representation went hand in hand with conceptualizations of the object under study.

But in the ears of some ornithologists, including Saunders, documentary infidelity was not the only problem: they also deplored the exclusion of people unable to read music. ${ }^{6}$ Their alternatives did not go as far as 
Mathews's notation, but were truly graphical or combined graphicswaves, straight lines, dots, dashes - with more traditional syllables to capture and evoke the sounds of birds. One advocate of such systems, the Canadian zoologist Bill Rowan, even promoted a shorthand script that aimed less for accuracy than for a "simplicity, plasticity and adaptability" allowing non-musicians to read and notate bird sound (Rowan 1925, cited in Bruyninckx 2013: 50). This was particularly important for a field science that depended on the input of amateurs as much as on that of professional ornithologists.

The issue of the best notation system for bird sound had much in common with to the problem of transcribing folk music and non-Western music. In musicology and ethnomusicology, the debate took off soon after the introduction of the phonograph for recording folk and non-Western music in the early 1890s in the United States and Europe. Among those involved were folk-oriented composers Béla Bartók and Zoltán Kodály, as well as music psychologists and ethnomusicologists (Stockmann 1979: 207-208). Highly influential was the 1909 "Proposal for the Transcription of Exotic Melodies" by Otto Abraham and Erich von Hornbostel. These two German scholars welcomed the rapidly expanding collections of phonograph recordings of non-Western music, to which von Hornbostel contributed as curator of the PhonogrammArchiv in Berlin (Mundy 2009: 218). They worried, however, that these collections would remain "dead capital" if ethnologists and musicologists did not create a standardized form of notation enabling them to compare the recordings (Abraham and von Hornbostel 1909: 1). They did not want to end up like linguists, who had developed so many different diacritical signs for phonological work that-in Abraham and von Hornbostel's view - they had seriously complicated their lives as researchers.

The transcription of non-Western languages, so the Americanist Brian Hochman has shown, had been a hot issue ever since ethnologist Franz Boas claimed, in his 1889 essay "On Alternating Sounds," that the Western ethnographic ear perceived alternations in the pronunciation of certain indigenous languages differently from the way native speakers themselves did. The admission of this "sound-blindness" and the wish to preserve languages resulted in enthusiasm for new orthographical techniques in literature and an archival shift to phonographic recording in the study of language and culture (Hochman 2010: 531-533). The phonograph could record languages "exactly" as the natives uttered them, 
and reproduce music as it had once been made. As the American music psychologist and ethnomusicologist Benjamin Ives Gilman wrote: "It can be interrupted at any point, repeated indefinitely, and even within certain limits magnified, as it were, for more accurate appreciation of changes in pitch, by increasing the duration of the notes" (Gilman 1891, cited in Hochman 2010: 541). The phonograph offered Gilman what Hochman calls a "culturally sealed container" for collecting and comparing "auditory specimens" free from field distractions (542).

Abraham and von Hornbostel fully acknowledged that Western notation did not do justice to non-Western music. At the same time, they wanted to modify the existing system as little as necessary, given that innovations in printing were costly and novel forms of notation were hard to learn and remember. For these reasons, they rejected systems that required extra lines beyond the usual five, something proposed by Gilman in 1908 and the composer Busoni in 1907. Graphic notation might be useful to show the curves of a melody, they conceded, but in principle notation should be done in musical staff in a simple key close to the original pitch, if necessary with a system of signs that combined sharp and flat to indicate recurrent deviations and +and - for tones between the half tones of the Western system. If pitch was unclear or noise-like, staff without heads was useful. Abraham and von Hornbostel proffered an extensive table of signs for exotic ways of phrasing, but continued to struggle with the notation of timbre, a classic problem in conventional music notation. The table used instrumentation to express tone color and had very few signs for ways of playing that evoked particular timbres, such as ${ }^{\circ}$ for flageolets. In addition, they endorsed Alexander J. Ellis's system of cents, introduced in 1885, which enabled absolute differences in pitch, or frequency expressed in "Herz," to be translated into relative distances between tones. One hundred cents stood for a half-tone difference and 700 cents for the seven half tones of a fifth; any number in between expressed microtonal deviations (Abraham and von Hornbostel 1909: 19). This plethora of suggestions indicates that, whereas the documentary fidelity of the phonograph was praised in ethnomusicological settings, graphic notation was far more contested as a method of standardization.

Standardizing notation was also an issue in dance. A short excursion into the debates in this field will prove helpful for my discussion of embodied versus mechanical notation in knowledge making in the penultimate section of this chapter. Folk-dance researchers notated dance 
using verbal descriptions and Western music notation combined with symbols expressing the movements of hands and feet (Douglas 1937: 114-116; Kenworthy Schofield 1928: 23-24). In 1935, on the occasion of a folklore conference and festival in London, the British diplomat and folklore researcher Rodney Gallop urged international agreement on a "formula." Not that such a formula could replace description; it "would give only an approximate idea of each dance, but it would enable the points in common between any two or more dances to be quickly picked out and the Highest Common Factor, to borrow a mathematical term, to be established between them" (Gallop 1935: 79). Several colleagues agreed, although one, the Oxford archaeologist and professor of ancient history John Lynton Myres, added that in creating such a nomenclature, folklorists would encounter the same problems of classification as ornithologists and zoologists had done (Myres in Gallop 1935: 82). They would still have to choose between the many systems used so far: verbal description; musical notation; musical notation enriched with words, figures, and steps; and the graphic notation of foot movements (Caravaglios 1935, 129-130).

Another commentator on Gallop's lecture, the Austrian folklorist Richard Wolfram, rejected the very idea of a truly universal system, as each type of dance required its own notation. Moreover, one could only really learn a dance by observing and interviewing the performers themselves (Wolfram in Gallop 1935: 82). And organologist Curt Sachs, also present at Gallop's presentation, warned that a notation system focusing on the component parts should not stop folklorists from approaching dances "as a whole." Instead of recording dances through a system of symbols, he suggested, they should "try the experiment of photographing a dance in the dark, with lights attached to the heads and limbs of the dancers." This would record the curves described by the dancers' bodies, from which the necessary comparisons and conclusions could be drawn (Sachs in Gallop 1935: 83).

Sachs thus favored the mechanical registration of dance, in the form of an abstraction of movements by observing the lines of the lights, whereas others preferred the lines of manual graphic notation. From the late nineteenth century, systems of manual graphic notation were also suggested in medicine, as an alternative to the existing wide variety of verbal descriptors. One of these systems applied metrical signs used in poetry (Martin and Fangerau 2011: 305). As historian Lisa Gitelman has shown, converting "aural experiences into inscribed evidence" beyond 
traditional script was a broader nineteenth-century preoccupation. One of Gitelman's examples is the rise of shorthand systems, or "phonography," in this case referring to the representation of "the sounds of speech on paper" (1999: 185). In medical practice, however, proposals to use graphic notation for plotting medical listening experiences once again led to a profusion of different sign systems.

For the case of German-language heart medicine, the medical historians Michael Martin and Heiner Fangerau (2011, 306ff) have explained that physicians tried to remedy the subjectivity of these codes around the turn of the twentieth century by introducing semi-manual notation systems. For example, they attempted to discipline the physicians' jottings through the use of a pre-formatted notation scheme. Because that still relied on individual physicians' observations, others proposed devices for the mechanical registration of sound that would be entirely independent of doctors' individual perception. These registration machines transformed sound waves into visual curves via electric signals or through a sensitive membrane, building on earlier work by scientists in acoustics and psychophysiology and following the wave-oriented visualization conventions of science at that time. Despite debates about the accuracy of these systems (some notation systems affected the results), their basic assumptions were readily accepted in medical laboratories. Proponents argued that such registrations could show details beyond human observation and enabled comparison both across registrations and across observers.

Clinicians were less enthusiastic. Rendering their observations open to inspection by others, including patients, potentially undermined the exclusivity of their expertise, and thus threatened to weaken their professional jurisdiction. They also believed that the promised precision of the machines would be difficult and time-consuming to attain. The stethoscope, in contrast, not only assisted the doctor in a quick and efficient check of the patients' health, but also functioned as a token of the physician's expertise and experience, as a symbol of his clinical habitus and social standing. Added to that, the stethoscope lent itself to being embedded in the important moments of direct contact between doctor and patient. If the stethoscope provided some physical distance, it also helped to keep physical examination, diagnostic work, and talking to the patient within a single sensory and temporal frame. 


\section{Save the Patient: Survival of EMbOdiEd RepresENTATION}

From the late nineteenth century onward, ornithologists gradually embraced mechanical registration of bird sound by the cylinder phonograph. Yet even though several ethnologists, ethnomusicologists and zoologists incorporated Thomas Edison's phonograph in their work quite soon after its introduction to the market in 1878 and Emile Berliner's gramophone in 1887, ornithologists were not among the early adopters. Only caged birds could be brought close enough to the recording horn, and thus create the amount of acoustic energy, for their vocalizations to be recordable. The obsession of ornithologists like Saunders with achieving accurate and intelligible forms of manual notation may also have inhibited the growth of interest in mechanical recording, as Joeri Bruyninckx has suggested (2013: 49-50). The phonograph became far more relevant for ornithologists in the second half of the 1920s, with the rise of microphones and their capacity for electroacoustic amplification. This enabled the recording of birds where it mattered most: in their natural environment (Bruyninckx 2014: 44). It also coincided with the heyday of the ideal of mechanical objectivity, the automatic registration of phenomena without interference by the embodied subjectivity of researchers.

Indeed, Joeri Bruyninckx (2013) has shown, recordings were initially applauded for their ability to help overcome the subjectivity and imprecision of manual field notation (in other words, for their mimetic function). Sound recordings were also praised for their assistance in recalling and collecting bird sound (mnemonic function), in teaching novices the auditory recognition of particular bird species (didactic function), and, through their aesthetic appeal, in tempting a wide audience of lay birdwatchers to contribute to ornithology (alluring function). By the end of the 1920s, the broadcasting industry was fueling the appropriation of sound recording equipment, including sound cameras, in field work by hiring naturalists to make recordings for radio use (Bruyninckx 2012: 133; 2015: 349-350). Yet mechanical recording merely postponed the problems of manual notation and its standardization to the research phase after returning from the field. It resulted in a repeatability of listening that, as we have seen, also articulated the shortcomings of classical musical notation for bird sound and made ornithologists ask for a notation that was both enriched and systematized (Bruyninckx 2013: 49). 
In the 1950s, the use of spectrography to visualize the frequency and intensity of sound across time started to dominate ornithological research. Many ornithologists welcomed mechanical visualization in the form of sound spectrograms, as it enabled an interesting focus on short calls and phrases in bird sound, creating "stills" of fragments of even the most rapidly alternating bird sounds. As Rachel Mundy has stressed, spectrographs also helped ornithologists to cope with the fact that bird sounds "often occur outside the human hearing range" (Mundy 2010: 180). Moreover, sound spectrograms permitted levels of standardization and distribution - or, in a Latourian sense, inscription, synoptic presentation, superimposition, and translation on paper-that they thought were more difficult to establish for manual notation. This increasing preference for mechanical visualization occurred not only in ornithology, but also in many other sciences of sound, such as acoustics, psychoacoustics, and phonology (Rieger 2009). That trend will be discussed in more detail in Chapter 4.

Why, then, did non-automatic, embodied registration practices survive despite the general trend towards mechanical objectivity and automatic registration? Even the heroes of ethnomusicological recording Abraham and von Hornbostel had to admit in 1909 that making mechanical recordings was not possible in every single situation. When it was not, manual notation could still be useful, provided it was done critically and with great care. Such care implied first learning to sing or play the music oneself, and then having an exceptionally musical member of the culture under study-musical in the terms of that culture-check whether the researcher had grasped the music correctly. Only after these steps should the music be translated into notation. Prepared in this way, manual notation could be highly instructive: the process of transforming the act of music-making into manual notation would enable the researcher to understand issues such as complex drum techniques and intricate melodic structures from within (Abraham and von Hornbostel 1909: 15). A similar argument had been made about dance by folklore specialist Wolfram in the mid-1930s, though his interest was not the opposition between manual and mechanical but between idiosyncratic and standardized notation. In both cases, the idea was that forms of manual notation linked to music-making or dancing by the researcher him- or herself would enhance the quality of the notation-not only in its mimetic dimension, but also in terms of analytical depth. Moreover, manual notation was a relatively slow process. As ethnomusicologist Helen Heffron 
Roberts claimed in 1931, this created opportunities for questions to arise, to the singers for instance, which would not occur when making phonographic recordings (Brady 1999: 73).

It is almost as if these ethnomusicologists and folklorists had read recent work by the British anthropologist Tim Ingold (2007). In his comparative anthropology and history of the line, Ingold distinguishes manual, gestural sketching from printing because it embodies a way of knowing that is, in his view, more true to how people experience their environment than mechanical printing can be: in real life, "we perceive the environment not from a stationary point ... but in the course of our movement along what [James] Gibson calls 'a path of observations' ... In the freehand sketch, the movement of the observer relative to a stationary feature is translated into the movement of the line depicting that feature relative to a viewer who is now stationary" (2007: 166). It was in the connection between bodily movement-learning to sing, play, or dance to particular music - and the subsequent manual notation of music that Abraham, von Hornbostel, and Wolfram situated a particular understanding, just as Ingold does. Even if they did not make it explicit, they seem to consider this understanding to be tacit yet transferable through its embodied transcription. For them, the epistemological value of manual notation depended on its sensory calibration in embodied music-making.

Another set of explanations for the survival of manual notation and other forms of embodied representation revolves around issues of urgency, efficiency, and dependency. Just as ethnomusicologists did not always have their recording equipment on standby, ornithologists sometimes had to rely on shorthand scribbles, for instance when an interesting bird made itself heard just as the recorder batteries ran out. In those cases, immediate manual notation was, and is, both urgent and highly efficient.

But manual notation has also been found efficient in situations of a different kind. In one of the systems that was introduced in the late nineteenth century and has survived until today, lung sounds are notated in terms of their occurrence within the respiratory cycle, usually as ascending and descending lines denoting inhalation and exhalation. "The length of the line indicates variations in the duration of the breath sound; the pitch (high or low) is represented by the line's angle; intensity (loud or soft) is illustrated by the thickness of the line" (Van Drie 2013: 182). In another system, a variety of dots, squiggles, and waves 
are sketched onto a two-dimensional outline of the lungs and shared in learning situations (Lachmund 1999: 428). As Anna Harris has shown in her ethnographic study of a medical school in Melbourne, doctors training novices in stethoscopic listening often create these lines in the air by gesticulating with their hands while mimicking sounds, or make "drawings of respiratory rhythms and heart murmurs" with whiteboard markers to evoke particular sounds and direct students' attention to them (Harris and Van Drie 2015: 103). Doctors also encourage students to carry out "auto-auscultation," touching and listening to their own bodies in order to grasp their teachers' references to sound (Rice 2013: 19, 137ff). By tapping on their thighs, for instance, they may understand what it means to hear and feel a "dull sound," or, to learn "to be affected" (Harris 2015: n.p.; 2016: 46).

Other embodied forms of representing sound survived as well. In the guild-like context of German car repair shops, as we have seen, exchanges of verbal descriptions of sound remained important for the analysis of car engine problems, both between experienced mechanics, and between master and apprentice (Krebs 2012b, 2014a). And even vocalizations of sound did not entirely disappear. An example comes from Alexandra Supper's research on the sonification community (2012). She attended three conferences organized by the International Community for Auditory Display (ICAD); interviewed its founding father Gregory Kramer and thirty-three other sonification practitioners between 2008 and 2011; studied dissertations, conference proceedings, and journal articles on sonification; attended sonification performances, talks, and workshops; and experimented with sonification herself using the audio synthesis programming language SuperCollider. Supper mentions Thomas Hermann's vocal sonifications of EEGs, in which data are deliberately made to sound like human vowel sounds in order to enable "data karaoke," a way of mimicking sonified data with one's own voice. This is particularly useful, Hermann claims, when sonification experts and clinicians collaborate on the interpretation of EEG data: it helps the collaborators to "communicate structures and patterns in EEG data by mimicking the patterns with their own voice" (Hermann et al. 2006: 6, cited in Supper 2016: 76).

In such cases, vocalizations, verbal descriptions, and manual notations are not only fast and efficient, but also constitute important epistemological work, similarly to the mathematical writing on blackboards discussed by Barany and MacKenzie (2014). There, "augmentations, 
annotations, and elisions" on the spot are crucial, and for students the meticulous transcription of those jottings is an embodied entry into thinking along and understanding the math. While such notes may seem to serve as mnemonic devices, the act of note-taking itself is actually at the heart of opening up and grasping knowledge. In fact, the mathematicians who contributed to Barany and MacKenzie's study acknowledged that they rarely returned to their notes, not even those on scrap paper. The notes hardly ever left "the sites in which they were produced" (p. 119). In contrast to Latour's focus on inscriptions as immutable mobiles, Barany and MacKenzie suggest treating the blackboard and scrap-paper scribbles as "immobilized mutables" that themselves constitute creative work (p. 118). In similar ways, vocalizing, verbally describing, and manually transcribing sound transforms sound into sound, sound into words, and sound into images to enact knowledge in close temporal, spatial, and embodied connection with the observation, analysis and explication of the phenomenon concerned.

The situations just described often involve a form of hierarchy, in which one individual - a patient, a student, a motorist, a person on board of a ship equipped with sonar-is dependent on the auditory diagnostic skills of another. This figure- a doctor, a teacher, a mechanic, a sonar operatorhas professional jurisdiction about tacit (at times, even secret) knowledge. This both enables and demands a temporary suspension of disbelief by the dependent party. Finally, reading Ingold again helps us understand the special significance of manual notation in situations involving training. Ingold stresses that reading a text is fundamentally different from reading a musical score. Whereas the former is about "taking in" meaning, working "inward," the latter is about "acting out the instructions inscribed in the score," working "outward" (Ingold 2007: 11). In training sessions, the outward direction of sensory instruction through notation or scores is what helps to bring teacher and student onto the same plane.

\section{Conclusions}

This chapter has attended particularly to the representation of sound across a variety of disciplines that use sound as a portal for understanding bodies, machines, and other objects of study. It has shown how talking about and transcribing sound in the sciences-whether through verbalizing sound, musical staff notation, or non-automatic graphic notation-both reflected and co-constituted the objects at stake. It has also 
discussed how and why non-automatic registration of sound survived in some settings and situations despite the rise of mechanical recording.

In late nineteenth-century and early twentieth-century sonar research, medicine, automotive engineering, car mechanics, and ornithology, the use of metaphors, onomatopoeia, and synesthetic translations was very important. In the metaphors, comparisons with sounds familiar from shared soundscapes predominated, ranging from the sounds of human voices and animals to those of natural phenomena, machines, and musical instruments. Two domains, medicine and automotive engineering, witnessed the gradual rise of a dual approach to sound. One aspect was direct sound mapping and the creation of fine-grained classifications and tables of sound that positively referred to particular problems. The other started from a differential diagnosis in which sonic signs merely indicated broad categories of potential problems, the cause of which then needed to be specified through exclusion-that is, negatively. The first strategy was linked to settings that allowed a local and embodied sharing of tacit knowledge; the second thrived in situations where that was not possible.

In most of the sciences and science-related professions discussed in this chapter, musical staff notation played an only marginal role. The exception was ornithology, in which bird sound was initially defined as bird song and music, and could thus follow fields such as music, musicology, ethnomusicology, and folk dance in using musical staff notation in combination with syllabic notation. But in both ornithology and music-related fields, musical staff notation started to receive a more critical press in the first decades of the twentieth century. In music, most of the critics-among whom were many composers, ethnomusicologists, and folklorists - demanded either an expansion of musical staff notation or the introduction of graphic notation in order to account for sounds that could not be captured by conventional musical notation, such as noises, microtones, complex rhythms, and non-stable metrics. In ornithology, arguments that musical staff notation was unnecessarily elitist and that only new forms of notation could capture the rich vocabulary of bird communication-as opposed to bird song-favored graphic notation until sound spectrograms became the standard for visualizing sound.

Despite the seemingly overwhelming victory of mechanical recording in combination with the sound spectrograph, non-automatic and manual recording of sound survived for particular purposes. Some researchers celebrated the analytical strength of embodied musical staff notation, others the efficiency of its simplicity in the field or on the ward, whether 
for urgent recording when no mechanical recording equipment is available or as a way of evoking sound on-the-spot. Moreover, as musical staff and graphic notation are also instructions for performing sound, its manual forms are highly functional in situations where future expert listeners are being trained in the sonic cultures of their profession, as well as in professional cultures where people have to communicate sound immediately in order to "save the patient."

As well as talking about sound and transcribing sound, this chapter has addressed the contexts in which scientists, doctors, and engineers turned to sound as a source of knowledge in the first place. One final example highlights the contingency of these situations. Discussing the emergence of forerunners to the Geiger-Müller counter in the late 1910s, Axel Volmar (2015) has argued that auditory detection instruments resulted from the desire to measure radiation at a more granular level than was permitted by existing visual techniques. This was done by making the ionization of gases through radiation not only visible, but also audible, with the help of telephones, amplifiers, and later loudspeakers. Telephones responded faster than electrometers with photographic equipment and did not require darkened rooms. The ear also processed such information more quickly than the eye, and discovering the causes of the sounds promised a better understanding of the differences in intensity between $\alpha$ and $\beta$ radiation.

Volmar shows that without the audio technologies available at the time, it would not have been possible to construct the sounding radiation detectors. But the growing interest in detection by auditory means was also buttressed by widely shared auditory experiences of the World War I front, in which some of the physicists working on the new detection technologies had participated. Forced to analyze the thunder of artillery for their own survival, millions of people had learned to use their ears in acquiring relevant knowledge, and physicists' frequent use of warlike acoustic rhetoric to describe discharge ("atomic drumfire") tapped into these experiences (p. 44). In 1928, Walter Müller, a Ph.D. student of physicist Hans Geiger, constructed the auditory radiation tube that would be given his and Geiger's name. In its mobile commercial version, the Geiger-Müller counter became an iconic tool for localizing sources of radiation, for better or worse. As early as 1929, Müller proudly reported in a letter to his parents that Albert Einstein considered the counter "the most sensitive organ of humanity" (Müller cited in Volmar 2015: 39). 
Certainly, the mere availability of audio technologies does not sufficiently explain the turn to sonic skills in this case, nor in the sciences at large. The phonograph was only taken up in the study of birds once the options for amplification of sound matched the ornithologists' growing focus on studying birds in natural settings. In medicine, the stethoscope was not only embraced so enthusiastically by doctors because it enabled them to examine patients without having to rely on their narratives, but also because it permitted male doctors a greater physical distance from female patients. Such historical contexts, however, do not preclude a systematic understanding of why and how scientists, engineers, and physicians listened and listen. That will form the topic of the next chapter.

\section{Notes}

1. A Google Scholar search on August 27, 2013, yielded 12,000 hits for publications about or using the semantic differential method since 2009. The automotive industry is one of the fields employing the method, for example for consumer evaluations of car sound (Cleophas and Bijsterveld 2012). The idea of using pairs of polar terms to study meaning was not Solomon's invention. His system came from research on synesthesia-a phenomenon in which sensations in a particular sensory mode recurrently trigger sensations in another mode-by the American psychologists Theodore F. Karwoski and Henry S. Odbert (1938).

2. For some images, see Booth 2 of our virtual exhibition on sonic skills, at http://exhibition.sonicskills.org/exhibition/booth2/doctors-distance-inlistening/ (last accessed April 21, 2017). There, we also explain the rise of specialized designs for the stethoscope head tailored to either cardiovascular or respiratory sounds.

3. On the International Lung Sounds Association and its Committee on Lung Sound Nomenclature, see http://www.ilsaus.com/pdf/lst_ ILSA_1976.pdf, at p. 34 (last accessed August 9, 2016).

4. For the Bobolink transcription, see the second image at http://exhibition. sonicskills.org/exhibition/booth4/notating-bird-song-and-sound/ (last accessed August 14, 2017).

5. See the first image at http://exhibition.sonicskills.org/exhibition/booth4/ graphical-notation-the-spectrograph/ (last accessed August 14, 2017).

6. Since the late nineteenth century, this had also be a concern in the world of music itself. Ana Maria Ochoa Gautier has recently explained how the Colombian poet, composer, and musician Diego Fallón aimed to replace musical notation with orthographic notation-notation for the pronunciation of language - to facilitate the making and distribution of music 
(Gautier 2014). In Europe and North America, early twentieth-century educators promoted solmization, a system that names notes in terms of their relative rather than absolute position in a key (Whittaker 1924), the use of colored notes (for a discussion, see Wellek 1932), or klavarskribo, a form of graphical notation based on picturing the piano (Pot 1933).

\section{REFERENCES}

Abraham, O., \& von Hornbostel, E. M. (1909). Vorschläge für die Transkription exotischer Melodien. Sammelbände der Internationalen Musikgesellschaft, $11(1), 1-25$.

Barany, M. J., \& MacKenzie, D. (2014). Chalk: Materials and Concepts in Mathematics Research. In C. Coopmans, J. Vertesi, M. Lynch, \& S. Woolgar (Eds.), Representation in Scientific Practice Revisited (pp. 107-129). Cambridge: MIT Press.

Bijsterveld, K. (2007). Weg van gelwid: Hoe de auto een plaats werd om tot rust te komen. Maastricht: Universiteit Maastricht.

Bijsterveld, K. (2012). Listening to Machines: Industrial Noise, Hearing Loss and the Cultural Meaning of Sound. In J. Sterne (Ed.), The Sound Studies (pp. 152-167). New York: Routledge.

Bijsterveld, K., \& Krebs, S. (2013). Listening to the Sounding Objects of the Past: The Case of the Car. In K. Franinović \& S. Serafin (Eds.), Sonic Interaction Design (pp. 3-38). Cambridge: MIT Press.

Bijsterveld, K., Cleophas, E., Krebs, S., \& Mom, G. (2014). Sound and Safe: A History of Listening Behind the Wheel. Oxford: Oxford University Press.

Brady, Erika. (1999). A Spiral Way: How the Phonograph Changed Ethnography. Jackson: University Press of Mississippi.

Bruyninckx, J. (2012). Sound Sterile: Making Scientific Field Recordings in Ornithology. In T. Pinch \& K. Bijsterveld (Eds.), The Oxford Handbook of Sound Studies (pp. 127-150). Oxford: Oxford University Press.

Bruyninckx, J. (2013). Sound Science: Recording and Listening in the Biology of Bird Song, 1880-1980 (Ph.D. thesis, Maastricht University).

Bruyninckx, J. (2014). Silent City: Listening to Birds in Urban Nature. In M. Gandy \& B. Nilsen (Eds.), The Acoustic City (pp. 42-48). Berlin: Jovis.

Bruyninckx, J. (2015). Trading Twitter: Amateur Recorders and Economies of Scientific Exchange at the Cornell Library of Natural Sounds. Social Studies of Science, 45(3), 344-370.

Busoni, F. (1962/1907). Sketch of a New Esthetic of Music. In Three Classics in The Aesthetic of Music (pp. 75-102). New York: Dover.

Caravaglios, C. (1935). The Collection and Transcription of Folk-Dances. Journal of the English Folk Dance and Song Society, 2, International Festival Number, 127-135. 
Cleophas, E., \& Bijsterveld, K. (2012). Selling Sound: Testing, Designing and Marketing Sound in the European Car Industry. In T. Pinch \& K. Bijsterveld (Eds.), The Oxford Handbook of Sound Studies (pp. 102-124). Oxford: Oxford University Press.

Cowell, H. (1932). Henry Cowell schrijft ons. Maandblad voor Hedendaagsche Muziek, 1(12), 90-91.

Douglas, M. (1937). Manx Folk Dances: Their Notation and Revival. Journal of the English Folk Dance and Song Society, 3(2), 110-116.

Gallop, R. (1935). Systematization of Motives in the Ceremonial Dance. Journal of the English Folk Dance and Song Society, 2, International Festival Number, 79-83.

Gautier, A. M. O. (2014). Aurality: Listening \& Knowledge in NineteenthCentury Colombia. Durham, NC: Duke University Press.

Gerard, P. (2002). Secret Soldiers: The Story of World War II's Heroic Army of Deception. New York, NY: Dutton.

Gitelman, L. (1999). Scripts, Grooves, and Writing Machines: Representing Technology in the Edison Era. Stanford, CA: Stanford University Press.

Goodwin, S. (2010). Sonic Warfare: Sound, Affect, and the Ecology of Fear. Cambridge: MIT Press.

Harris, A. (2015). Autophony: Listening to Your Eyes Move. Somatosphere: Science, Medicine and Anthropology. Available at http://somatosphere. net/2015/06/autophony-listening-to-your-eyes-move.html. Last accessed August 18, 2017.

Harris, A. (2016). Listening-Touch Affect and the Crafting of Medical Bodies Through Percussion. Body \& Society, 22(1), 31-61.

Harris, A. \& Van Drie, M. (2015). Sharing Sound: Teaching, Learning and Researching Sonic Skills. Sound Studies: An Interdisciplinary Journal, 1(1), 98-117.

Hochman, B. (2010). Hearing Lost, Hearing Found: George Washington Cable and the Phono-Ethnographic Ear. American Literature, 82(3), 519-551.

Ingold, T. (2007). Lines: A Brief History. Milton Park: Routledge.

Karwoski, T. F., \& Odbert, H. S. (1938). Color-Music. Psychological Monographs, 50, 2.

Kenworthy Schofield, R. (1928). Morris Dances from Field Town. Journal of the English Folk Dance Society, 2, 22-28.

Krebs, S. (2012a). "Notschrei eines Automobilisten" oder die Herausbildung des Kfz-Handwerks in Deutschland. Technikgeschichte, 79(3), 185-206.

Krebs, S. (2012b). "Sobbing, Whining, Rumbling": Listening to Automobiles as Social Practice. In T. Pinch \& K. Bijsterveld (Eds.), The Oxford Handbook of Sound Studies (pp. 79-101). Oxford: Oxford University Press.

Krebs, S. (2013). Von Motorkonzerten und aristokratischer Stille: Die Einführung der geschlossenen Automobilkarosserie in Frankreich und 
Deutschland, 1919-1939. In R.-J. Gleitsmann \& J. Wittmann (Eds.), Innovationskulturen um das Automobil: Von gestern bis morgen (pp. 77-99). Königswinter: Heel.

Krebs, S. (2014a). "Dial Gauge versus Sense 1-0": German Car Mechanics and the Introduction of New Diagnostic Equipment, 1950-1980. Technology and Culture, 55(2), 354-389.

Krebs, S. (2014b). Diagnose nach Gehör? Die Aushandlung neuer Wissensformen in der Kfz-Diagnose (1950-1980). Ferrum: Wissensformen der Technik, 86, 79-88.

Lachmund, J. (1999). Making Sense of Sound: Auscultation and Lung Sound Codification in Nineteenth-Century French and German Medicine. Science, Technology and Human Values, 24(4), 419-450.

Marsden, W. J. M. (1927). Some Observations on Bird Music. Music \& Letters, $8(3), 339-344$.

Martin, M., \& Fangerau, H. (2011). Töne sehen? Zur Visualisierung akustischer Phänomene in der Herzdiagnostik. NTM Zeitschrift fur Geschichte der Wissenschaften, Technik und Medizin, 19(3), 299-327.

Maslen, S. (2015). Researching the Senses as Knowledge: A Case Study of Learning to Hear Medically. The Senses of Society, 10(1), 52-70.

Mundy, R. (2009). Birdsong and the Image of Evolution. Society and Animals, $17(3), 206-223$.

Mundy, R. (2010) Nature's Music: Birds, Beasts, and Evolutionary Listening in the Twentieth Century (Ph.D. thesis, New York University).

Osgood, C. E., Suci, G. J., \& Tannenbaum, P. H. (1957). The Measurement of Meaning. Urbana: University of Illinois Press.

Pot, C. (1933). Klavarskribo: Proeve van een vereenvoudiging van ons notenschrift (Slot). Maandblad voor Hedendaagsche Muziek, 2(4), 129-130.

Reichert, S., Gass, R., Brandt, C., \& Andrès, E. (2008). Analysis of Respiratory Sounds: State of the Art. Clinical Medical Insights: Circulatory, Respiratory and Pulmonary Medicine, 2, 45-58.

Rice, T. (2013). Hearing and the Hospital: Sound, Listening, Knowledge and Experience. Canon Pyon: Sean Kingston Publishing.

Rieger, S. (2009). Schall und Rauch: Eine Mediengeschichte der Kurve. Frankfurt am Main: Suhrkamp Verlag.

Ross, C. D. (2004). Sight, Sound, and Tactics in the American Civil War. In M. Smith (Ed.), Hearing History: A Reader (pp. 267-278). Athens: University of Georgia Press.

Russolo, L. (1986/1916). The Art of Noises. New York: Pendragon Press.

Schwartz, H. (2012). Inner and Outer Sancta: Earplugs and Hospitals. In T. Pinch \& K. Bijsterveld (Eds.), The Oxford Handbook of Sound Studies (pp. 273-297). Oxford: Oxford University Press. 
Solomon, L. N. (1954). A Factorial Study of the Meaning of Complex Auditory Stimuli (Passive Sonar Sounds). Urbana: University of Illinois.

Sovijärvi, A. R. A., Dalmasso, F., Vanderschoot, J., Malmberg, L. P., Righini, G., \& Stoneman, S. A. T. (2000). Definition of Terms for Applications of Respiratory Sounds. European Respiratory Review, 10(77), 597-610.

Stockmann, D. (1979). Die Transkription in der Musikethnologie: Geschichte, Probleme, Methoden. Acta Musicologica, 51(Fasc. 2), 204-245.

Supper, A. (2012). Lobbying for the Ear: The Public Fascination with and Academic Legitimacy of the Sonification of Scientific Data (Ph.D. thesis, Maastricht University).

Supper, A. (2016). Lobbying for the Ear, Listening with the Whole Body: The (Anti-)Visual Culture of Sonification. Sound Studies: An Interdisciplinary Journal, 2(1), 69-80.

Van Drie, M. (2013). Training the Auscultative Ear: Medical Textbooks and Teaching Tapes (1950-2010). The Senses and Society, 8(2), 165-191.

Volmar, A. (2012). Klang als Medium wissenschaftlicher Erkenntnis: Eine Geschichte der auditiven Kultur der Naturwissenschaften seit 1800 (Ph.D. thesis, Universität Siegen).

Volmar, A. (2013). Listening to the Cold War: The Nuclear Test Ban Negotiations, Seismology, and Pyschoacoustics, 1958-1963. In A. Hui, J. Kursell, \& M. Jackson (Eds.), Music, Sound and the Laboratory from 17501980. Osiris, 28, 80-102.

Volmar, A. (2014). In Storms of Steel: The Soundscape of World War I and Its Impact on Auditory Media Culture During the Weimar Period. In D. Morat (Ed.), Sounds of Modern History: Auditory Cultures in 19th-and 20th-Century Europe (pp. 227-255). New York, NY: Berghahn.

Volmar, A. (2015). Ein "Trommelfeuer von akustischen Signalen": Zur auditiven Produktion von Wissen in der Geschichte der Strahlenmessung. Technikgeschichte, 82(1), 27-46.

Wellek, A. (1932). Die Entwicklung unserer Notenschrift aus dem Tönesehen. Acta Musicologica, 4(3), 114-123.

Whittaker, W. G. (1924). The Claims of Tonic Solfa I. Music \& Letters, 5(4), 313-321.

Zwikker, C. (1934). De oorzaken van het geluid bij automobielen. In Anonymous, Verslag van het 'Anti-lawaai Congres,' georganiseerd te Delft, op 8 november 1934 door de Koninklijke Nederlandsche Automobile Club in samenwerking met de Geluidstichting (pp. 70-77). Delft: KNAC/Geluidstichting. 
Open Access This chapter is licensed under the terms of the Creative Commons Attribution-NonCommercial 4.0 International License (http:// creativecommons.org/licenses/by-nc/4.0/), which permits any noncommercial use, sharing, adaptation, distribution and reproduction in any medium or format, as long as you give appropriate credit to the original author(s) and the source, provide a link to the Creative Commons license and indicate if changes were made.

The images or other third party material in this chapter are included in the chapter's Creative Commons license, unless indicated otherwise in a credit line to the material. If material is not included in the chapter's Creative Commons license and your intended use is not permitted by statutory regulation or exceeds the permitted use, you will need to obtain permission directly from the copyright holder.

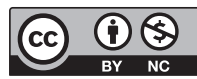

